Please do not remove this page

RMIT

UNIVERSITY

\title{
Growth of indium oxide nanostructures by thermal evaporation
}

Fechete, Alexandru; Wlodarski, Wojtek; Holland, Anthony; Kalantar-Zadeh, Kourosh

https://researchrepository.rmit.edu.au/esploro/outputs/9921860046401341/filesAndLinks?institution=61RMIT_INST\&index=null

Fechete, A., Wlodarski, W., Holland, A., \& Kalantar-Zadeh, K. (2006). Growth of indium oxide nanostructures by thermal evaporation. Proceedings of the 2006 International Conference on Nanoscience and Nanotechnology, 138-141. https://doi.org/10.1109/ICONN.2006.340570

Published Version: https://doi.org/10.1109/ICONN.2006.340570

Repository homepage: https://researchrepository.rmit.edu.au

(c) 2006 IEEE. Personal use of this material is permitted. However, permission to reprint/republish this material for advertising or promotional purposes or for creating new collective works for resale or redistribution to servers or lists, or to reuse any copyrighted component of this work in other works must be obtained from the IEEE.

Downloaded On 2023/04/26 18:13:50 +1000 


\title{
Growth of Indium Oxide Nanostructures by Thermal Evaporation
}

\author{
Alexandru C. Fechete, Wojtek Wlodarski, Anthony S. Holland, Kourosh Kalantar-zadeh \\ School of Electrical \& Computer Engineering \\ Sensor Technology Laboratory, RMIT University, GPO Box 2476V, Melbourne, VIC 3001, AUSTRALIA \\ Telephone: +61 3 9925-3690, Fax: +61 3 9925-2007 \\ Email: alex.fechete@ieee.org
}

\begin{abstract}
In this work, we report the synthesis and characterization of indium oxide nanostructures grown by thermal evaporation on silicon substrates with and without the presence of gold catalysts in the temperature range of 600 to $900^{\circ} \mathrm{C}$. These structures are in the form of nanobelts and nanorods with dimensions from a few micrometers in length and less than $200 \mathrm{~nm}$ in width. The growth processes involved in the formation of the nanostructures are the vapor-solid (VS) and vapor-liquid-solid (VLS) mechanisms where the former is responsible for growth when Au catalyst is used. Scanning Electron Microscopy was employed to characterize the morphology of nanostructures.
\end{abstract}

Keywords - Nanobelts, Nanorods, InO $_{x}$, Thermal evaporation, Vapor-transport techniques, Gold catalyst.

\section{INTRODUCTION}

The fabrication of one-dimensional nanostructures of semiconducting metal oxides such as nanorods, nanowires and nanobelts has recently attracted much attention. These nanostructures show novel physical and chemical properties and have potential applications in the development of electronic and optoelectronic devices [1, 2]. Additionally, the application of these structures in the sensor field is very promising due to their large surface to volume ratio [3]. Recently many researches have focused their attention on the fabrication of semiconducting oxide nanostructures with widebandgaps, such as indium oxide (direct bandgap energy in of $3.55 \sim 3.75 \mathrm{eV})$. Indium oxide $\left(\mathrm{InO}_{\mathrm{x}}\right)$ is an important transparent conducting oxide (TCO) material with many applications such as: window heaters, solar cells and flat panel displays [4]. It is also an insulator in its stoichiometric form, whereas in its nonstoichiometric form it behaves as a semiconductor material [5]. There are many reports on the synthesis of $\mathrm{InO}_{x}$ nanostructures in different dimensions and forms such as: nanowires [6] and nanobelts [7] using various methods. These include: physical evaporation [8], laser ablation [9], carbothermal reduction reaction [10] and a template-assisted approach using mesoporous silica [11]. Sensors based on field effect transistors with high sensitivity using $\mathrm{InO}_{\mathrm{x}}$ nanowires for toxic gas detection have also been fabricated [12].

In this paper, we report the synthesis and characterization of indium oxide $\left(\mathrm{InO}_{\mathrm{x}}\right)$ nanobelts and nanorods grown by thermal evaporation through vapor-solid (VS) and vaporliquid-solid (VLS) growth processes on polished silicon substrates. Synthesis was conducted with and without the presence of a gold catalyst.

\section{EXPERIMENTAL PROCEDURE}

The indium oxide nanorods and nanobelts were synthesized by thermal evaporation using $99.995 \%$ pure $\mathrm{In}_{2} \mathrm{O}_{3}$ powder as a source material (purchased from China Rare Metal Material Co. Ltd.). Approximately 3-5 g powder was loaded on an alumina boat and positioned in the central part of a $50 \mathrm{~cm}$ long horizontal quartz tube in a furnace (Fig. 1).

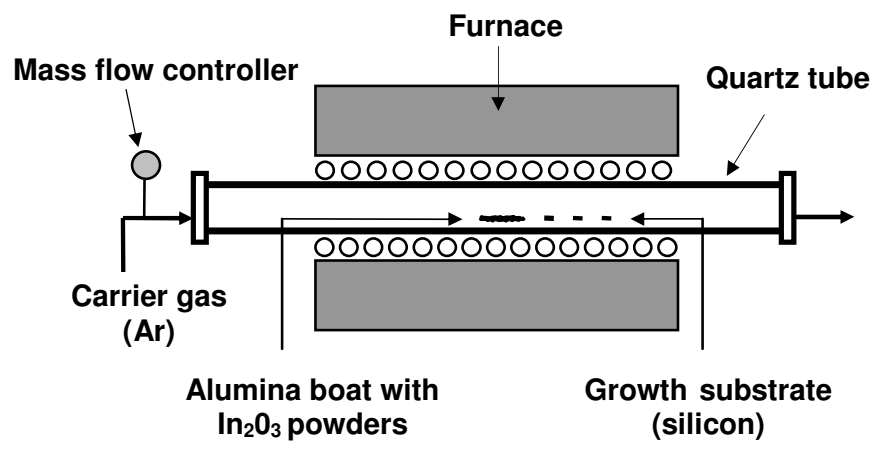

Figure 1. Schematic of the experimental apparatus used for the growth of $\mathrm{InO}_{\mathrm{x}}$ nanotructures.

Samples of one side polished silicon substrates with and without a $\mathrm{Au}$ catalyst layer were placed at distances of $7 \mathrm{~cm}$ (labeled as NSiAu for the sample with gold catalyst and for blank sample NSi), $10 \mathrm{~cm}$ (MSi and MSiAu) and $15 \mathrm{~cm}$ (FSiAu and FSi) from the source material in the tube. A thin layer of Au catalyst was deposited using a DC sputterer, which generated a green surface. During the thermal evaporation process a constant flow of pure Ar gas was maintained at $0.5 \mathrm{l} / \mathrm{min}$. The temperature of the furnace was rapidly increased with a heating rate of $50^{\circ} \mathrm{C} / \mathrm{min}$. and held for 30 minutes. The deposition temperature was varied from $600^{\circ} \mathrm{C}$ to $900^{\circ} \mathrm{C}$.

The dissociation process occurs at the constant flow of pure Ar when the heating of the $\operatorname{In}_{2} \mathrm{O}_{3}$ powders starts, thus the In vapors are carried to the sample regions where they condense forming nanorods or nanobelts. After cooling to room 
temperature, light yellow layers were found on the inner wall of the quartz tube. The growth mechanism of these nanostructures will be discussed later. The morphology and structure of the product was examined using a Philips XL30 scanning electron microscope (SEM).

\section{RESULTS AND DISCUSSION}

For temperatures below $650^{\circ} \mathrm{C}$ no nanostructure growth was observed. The nanostructures were discernable at temperature above $700^{\circ} \mathrm{C}$.

Figures $2 \mathrm{a}$ and $2 \mathrm{~b}$ show the SEM micrographs of the synthesized nanobelts at different magnifications obtained at the deposition temperature of $750^{\circ} \mathrm{C}$ on a blank silicon substrate (sample MSi). Randomly arranged nanobelts with a localized dense distribution can be seen with some of them appearing to be bent. The lengths of the nanobelts are of a few micrometers and have widths between 10 and $200 \mathrm{~nm}$.
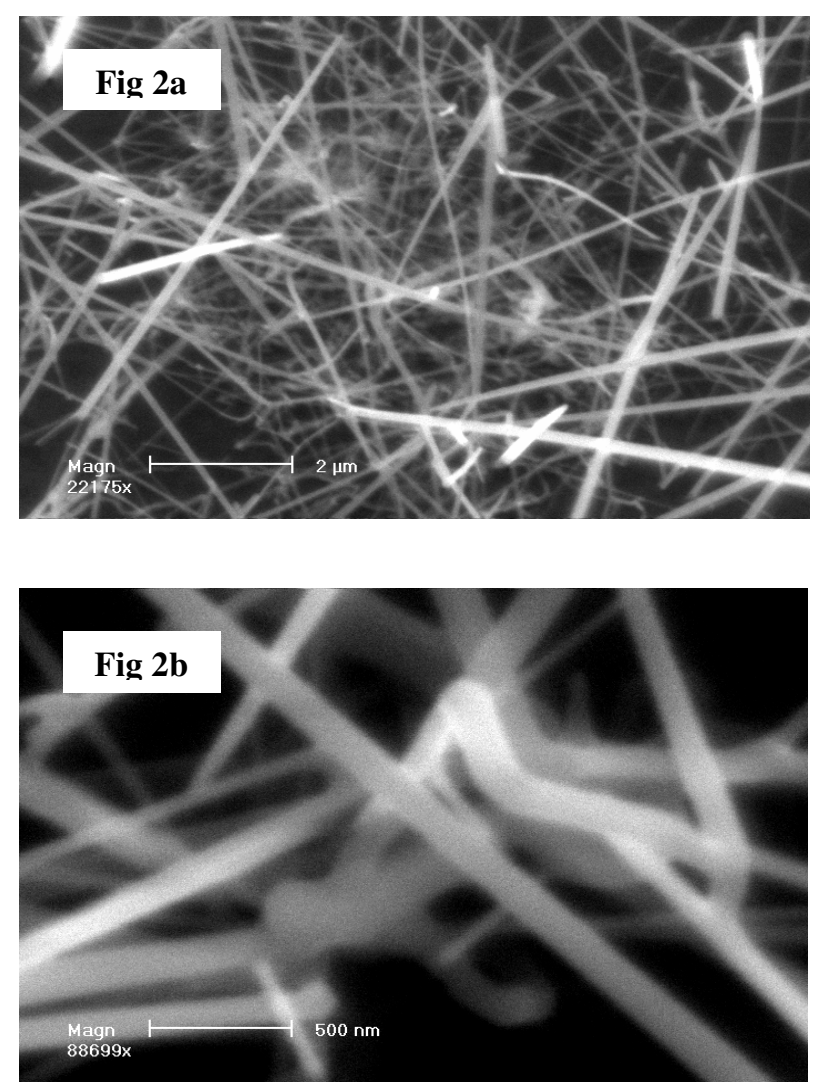

Figure 2. SEM micrographs of $\mathrm{InO}_{x}$ nanobelts on a silicon substrate (without Au catalyst) deposited at $750^{\circ} \mathrm{C}$. Different magnifications of the

MSi sample show: (a) the size , and (b) the shape of the nanobelts.

The nanostructures have a sparse distribution on the silicon substrate in some areas where they are formed in aglomerations with different geometrical shapes and dimensions. Figure $3 \mathrm{a}$ and $3 \mathrm{~b}$ shows nanobelts forming "nano-squares" with dimensions up to several tens of micrometers.
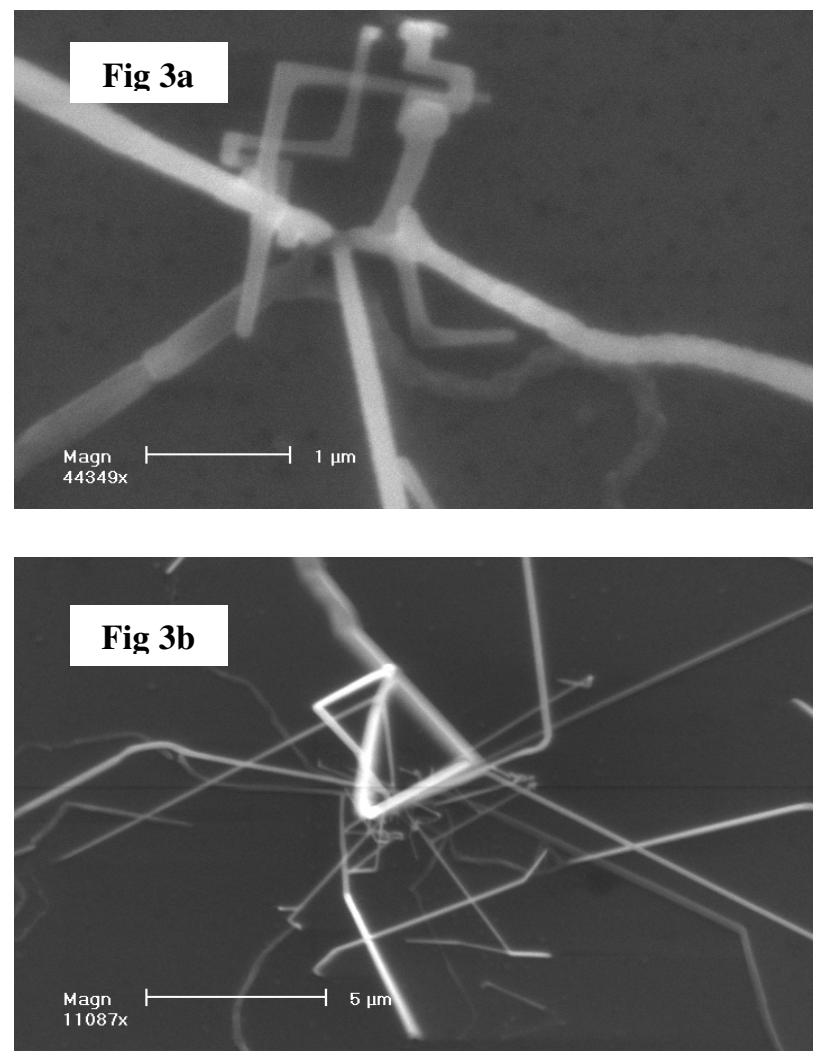

Figure 3. (a) and (b) SEM micrographs of $\mathrm{InO}_{\mathrm{x}}$ nanobelts on a silicon substrate (without Au catalyst) deposited at $750^{\circ} \mathrm{C}$. Different magnifications of the MSi sample show different shapes of the nanobelts.

The formation of nanobelts without the use of a gold catalyst is believed to be due to the vapor-solid growth mechanism [13].

A possible explanation of the vapor-solid (VS) growth process of the nanobelts is given by Z. R. Dai et al. The source material is assumed to vaporize in molecular species at high temperature and is composed of stoichiometric cation-anion molecules. At lower temperatures the molecules will condense onto the substrate forming small nuclei. The newly arriving molecules will continue to deposit on the nuclei, while the surfaces that have lower energy start to form as side surfaces. As the low-energy surfaces tend to be flat due to high mobility of the molecules, more molecules will be deposited in the growth front resulting in the fast formation of nanobelts [14].

The surface energy minimization can play an important role in the formation of nanowires and nanobelts [15]. It can be said also that the size of the nanobelts is determined by the growth temperature and kinetics of the crystal growth (supersaturation ratio). These are the two dominant processing factors in controlling the morphology of the products in the VS growth process [14]. Also it is well known that defects such as: dislocations, kinks, vacancies, scratches, grooves and ledges are favored sites that improve nucleation which results in the formation of nanostructures such as nanowires [16]. 
Figure 4 shows SEM micrographs of the indium oxide nanostructures obtained for the samples which have a very thin $\mathrm{Au}$ catalyst layer. In this case, the growth process involved is the vapor-liquid-solid (VLS) mechanism, which is also called catalysis growth [13]. In this mechanism, proposed for first time by Wagner and Ellis [16], the anisotropic crystal growth is guided by a droplet of liquid alloy. The droplet surface has a higher sticking coefficient and therefore a preferred absorption site for the vapor reactant. As the droplet becomes more saturated with the vapor reactant, different nanostructured growth will begin by the precipitation process of the reactant. The role of the liquid droplet in the growth process is similar to that of a catalyst in chemical reaction; the Au nanoparticle serve as the catalyst between the vapors feed and solid growth and influences the nanostructures' direction and diameter.

As can be seen from Fig. $4 \mathrm{a}$, at $750^{\circ} \mathrm{C} \mathrm{InO}_{\mathrm{x}}$ crystallites are formed around the $\mathrm{Au}$ particles, which agglomerated in clusters with dimensions larger than $1 \mu \mathrm{m}$. When samples were located further from the $\mathrm{In}_{2} \mathrm{O}_{3}$ source, the formation of both nanorods and nanobelts around crystallites could be observed, however they have a random distribution (Fig. 4b).

At $900^{\circ} \mathrm{C}$ the formation of nanorods around $\mathrm{Au}$ particle were observed. The diameter of these nanorods is dependent on the gold particle diameter, which is less than $250 \mathrm{~nm}$. The crystallites were homogenously scattered on the surface with distances between clusters being approximately $1 \mu \mathrm{m}$ (Fig.4c).
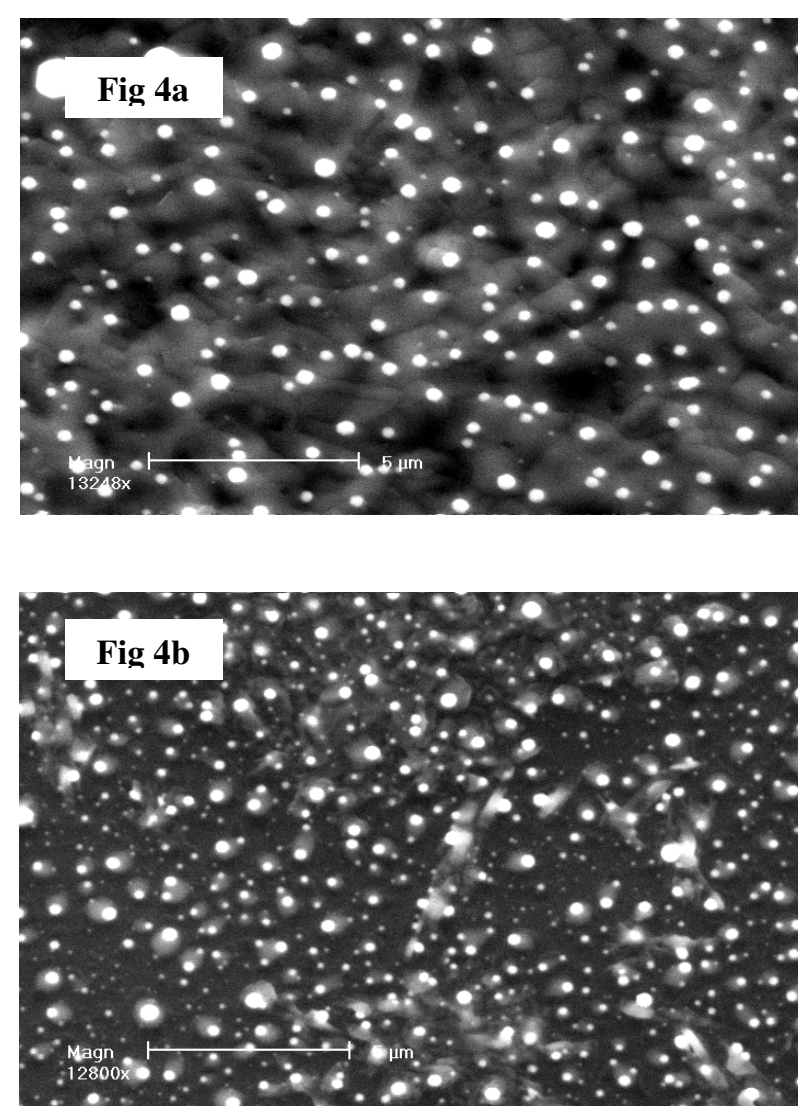

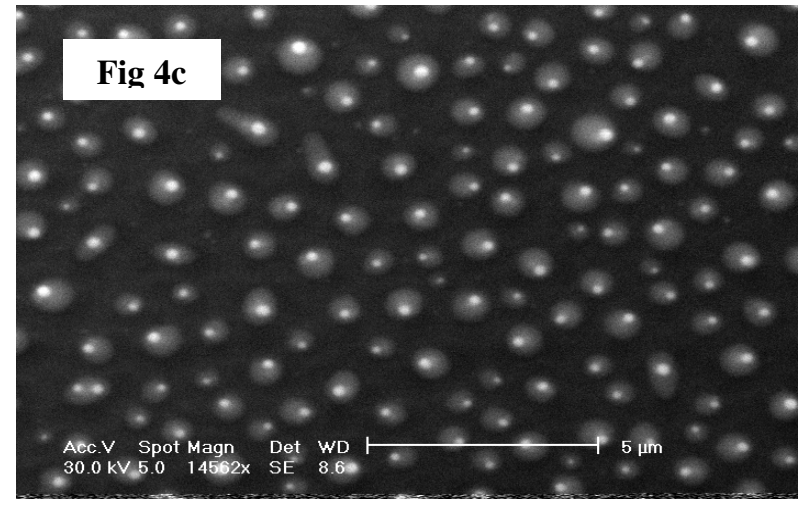

Figure 4. SEM micrographs of $\mathrm{InO}_{\mathrm{x}}$ nanostructured thin films on silicon (with $\mathrm{Au}$ catalyst) deposited at: (a) $750^{\circ} \mathrm{C}$ for $\mathrm{MSiAu}$ sample,

(b) $750^{\circ} \mathrm{C}$ for $\mathrm{FSiAu}$, and (c) $900^{\circ} \mathrm{C}$ for $\mathrm{MSiAu}$ sample.

\section{CONCLUSIONS}

In this work we presented $\mathrm{InO}_{\mathrm{x}}$ nanostructures obtained by thermal evaporation at different deposition temperatures with and without a gold catalyst layer.

The SEM analysis revealed the growth of nanobelts that were approximately 10-200 $\mathrm{nm}$ wide and a few micrometers long at $750^{\circ} \mathrm{C}$ when no catalyst was used. When a gold catalyst was used, homogenously scattered nanorods where obtained at $900^{\circ} \mathrm{C}$.

Work is presently in progress to optimize the deposition conditions and to further characterize these structures using transmission electron microscopy (TEM), X-ray diffraction (XRD) and to obtain a denser distribution of these nanostructures on the entire surface of the substrate for gas sensing applications.

\section{REFERENCES}

[1] C. Ma, D. Moore, Y. Ding, J. Li and Z. L. Wang, "Nanobelt and nanosaw structures of II-VI semiconductors", Int. J. Nanotechnology, vol. 1, pp. 431-451, 2004.

[2] Z. L. Wang, "Functional oxide nanobelts: Materials, properties and potential applications in nanosystems and biotechnology", Annual Review of Physical Chemistry, vol. 55, pp. 159-196, 2004.

[3] C. Baratto, E. Comini, G. Faglia, G. Sberveglieri, M. Zha and A. Zappettini, "Metal oxide nanocrystals for gas sensing", Sensors and Actuators B: Chemical ,vol. 109, pp. 2-6, 2005.

[4] F. Liu, M. Bao, K.L. Wang, C. Li, B. Lei and C. Zhou, "Onedimensional transport of $\operatorname{In}_{2} \mathrm{O}_{3}$ nanowires", Applied Physiscs Letter , vol. 86 , pp. 1-3, 2005

[5] G. Kiriakidis, N. Katsarakis, M. Bender, E. Gagaoudakis, and V. Cimalla, "InO $\mathrm{x}_{\mathrm{x}}$ thin films, candidates for novel chemical and optoelectronic applications", Mater. Phys. Mech., vol. 1, pp. 83-97, 2000.

[6] X. C. Wu, J. M. Hong, Z. J. Han and Y. R. Tao, , "Fabrication and photoluminescence characteristics of single crystalline $\mathrm{In}_{2} \mathrm{O}_{3}$ nanowire", Chemical Physics Letters, vol. 373, pp. 28-32, 2003.

[7] Z. W. Pan, Z. R.Dai, Z. L. Wang and K. Elissa, "Nanobelts of Semiconducting Oxides", Science, vol. 291, pp. 1947 - 1949, 2001.

[8] F. Zeng, X. Zhang, J. Wang, L. Wang and L. Zhang, "Large-scale growth of $\mathrm{In}_{2} \mathrm{O}_{3}$ nanowires and their optical properties", Nanotechnology, vol. 15 , pp. 596-600, 2004. 
[9] C. Li, D. Zhang, S. Han, X. Liu, T. Tang and C. Zhou, "Diametercontrolled growth of single-crystalline $\mathrm{In}_{2} \mathrm{O}_{3}$ nanowires and their electronic properties", Adv. Material, vol. 15 , pp. 143 - 146, 2003.

[10] C. Xiangfeng, W. Caihong, J. Dongli and Z. Chenmou, "Ethanol sensor based on indium oxide nanowires prepared by carbothermal reduction reaction", Chem. Physics Letters, vol. 399, pp. 461-464, 2004.

[11] H. Yang, Q. Shi, B. Tian, Q. Lu, F. Gao, S. Xie, J. Fan, C. Yu, Bo Tu, and D. Zhao, "One-step nanocasting synthesis of highly ordered single crystalline indium oxide nanowire arrays from mesostructured frameworks", J. A. Chem. Soc., vol. 125, pp. 4724-4725, 2003.

[12] D. Zhang, Z. Liu, T. Tang, X. Liu, S. Han, B. Lei, and C. Zhou, "Detection of $\mathrm{NO}_{2}$ down to ppb levels using individual and multiple $\mathrm{In}_{2} \mathrm{O}_{3}$ nanowire devices', Nano Letters, vol. 4, pp. 1919-1924, 2004.
[13] Z.L.Wang, "Nanobelts, nanowires, and nanodikettes of semiconducting oxides - from materials and nanodevices" , Adv. Mater., vol. 15, pp. 432-436, 2003.

[14] Z. R. Dai, Z. W. Pan and Z. L. Wang, "Novel nanostructures of functional oxides synthesized by thermal evaporation" , Adv. Funct. Mater., vol. 13, pp. 9-24, 2003.

[15] Z.R.Dai, Z.W.Pan and, "Controlled growth of one-dimensional oxide nanomaterials", Solid State Commun., vol. 118, pp. 351-356, 2001.

[16] M. Z. Atashbar and S. Singamanemi, "Room temperature gas sensor based on metallic nanowires", Sens. and Actuators : B, vol. 111-112, pp. 13-21, 2005.

[17] R. S. Wagner and W. C. Ellis, " Vapor-liquid-solid mechanism of single crystal growth“, Appl. Phys. Lett. , vol. 4, pp. 89-90, 1964. 